\title{
Operations Research in Ireland
}

\author{
(edited by Julian MacAirt, The Mercier Press, Cork and Dublin 1988: ISBN 0-85342- \\ 862-X)
}

\section{Reviewed by Brian Lenehan}

This book comprises contributions from a number of prominent practitioners of $O R$ in Ireland. The approach used, of each essay giving a historical synopsis and then one or more easily readable case studies, is very effective. The editor cannot have had an easy task in so constraining the authors without hampering their individuality. He succeeded. The reviewer has worked with a number of the contributors, and has close contact with the others. The contributions they have made to the efficiency and effectiveness of their organizations are understated. Like almost all OR people they should blow their own coals to some degree.

I was most interested in Richard Kavanagh's essay on energy forecasting. Because of our dependence on imported energy, this is a very relevant topic here. A lot of excellent work was done, progress was being made and then oil prices dropped. The urgency went out and interest in the work by the decision-makers evaporated. Is it always such, that when something is not urgent it is not important? Are OR people called in when the answer is required tomorrow and discarded when the answer cannot be provided in time? Many of the articles hint at a justification for analysis in such circumstances in the recurring theme that the "answer" is not the only outcome; that the insight and explanation of the system examined more than repay the investment in analysis. This could be the paradigm of OR.

A further common characteristic of the best OR practice is evident in many of the contributions, but it is best portrayed in Seamus O'Carroll's work on inflation and cash-flow. It is everything that an OR model should be: easily understood, comprehensive and profound. Like the Gettysburg address, most worthwhile things can be done on the back of an envelope.

For anyone practising OR or any Management Science in large organizations, the articles on the banks, the state bodies and the public service should be required reading. The techniques articles by Bannister and Neelamkavil are not for the non-OR reader and (though excellent in themselves) might have been published in a different volume.

The OR practitioner is advised to approach each problem from a value-free position. Not always easy; but hopefully achieved better than by Roy Johnston in his reference to the "Frankenstein monster created by CAP" when discussing bulk milk collection. It is unfortunate that Dr Johnston lets his prejudice show in an otherwise excellent piece on MSc. projects. The work done by his students has been the single most important facet of OR in Ireland.

One of the stated objectives of the book is to "have a representative cross-section of authors from those involved in OR in Ireland over the past two decades". There are two contributions from Northern Ireland, Queens' University Belfast and the University of Ulster. These mention the first-class work done there, particularly in the health and manpower-planning areas. The lists of contributors to OR Annual Conferences is witness to the interest and expertise to be found there. However, there is virtually no work described that was not completed more than ten years ago. This prompts a number of questions:

- does career/age advancement take one away from interesting, reportable OR work?;

- is OR being subsumed by other disciplines and the practitioners reporting to other societies?; or, most worryingly

- has OR, in Ireland and elsewhere, lost its drive and enthusiasm?

In producing this excellent book, Julian MacAirt does not seem to think so. I hope he is right. 